\title{
Epigallocatechin-3-gallate Promotes Osteoblastic Activity in Human Osteoblast-like Cells
}

\author{
Yuewen Peng ${ }^{1}$, Bin $\mathrm{Yu}^{1 *}$ and Fang $\mathrm{Liu}^{2}$ \\ ${ }^{1}$ Department of Trauma Orthopaedics, Southern Medical University Affiliated Nanfang Hospital, Guangzhou, ${ }^{2}$ Department of \\ Orthopaedics, The Second Hospital of Yueyang, Yueyang, China \\ ${ }^{\star}$ For correspondence: Email: yu_bin2000@sina.com; Tel: +86-20-61641741
}

Revised accepted: 28 December 2015

\begin{abstract}
Purpose: To investigate the effect of epigallocatechin-3-gallate (EGCG) on bone metabolism and osteoblastic activity.

Methods: MG-63 human osteoblast-like cells were treated with varied concentrations of EGCG. Alkaline phosphatase (ALP) activity and matrix mineralization assays were carried out on the treated and untreated MG-63 human osteoblast-like cells. Beta-catenin mRNA level was determined by quantitative real-time polymerase chain reaction (q-PCR).

Results: The results showed that EGCG treatment significantly increased ALP and mineralization activities at concentrations of 15 and $30 \mu \mathrm{M}$, in a dose-dependent manner. Furthermore, EGCG treatment significantly increased beta-catenin mRNA expression by $70.7 \pm 11.0$ and $126.7 \pm 35.1 \%$, respectively, at EGCG concentration of 15 and $30 \mu \mathrm{M}$. In addition, the stimulating effect of EGCG treatment on ALP activity was abolished by co-treatment with $\mathrm{ICl} 182,780$, an antagonist of estrogen receptor (ER). Again, the increase in beta-catenin MRNA, when treated with EGCG, was inhibited by co-treatment with ICI 182,780.

Conclusion: EGCG promotes osteoblastic activity in human osteoblast-like cells, by Wnt signaling through estrogen receptor (ER) pathway.
\end{abstract}

Keywords: Epigallocatechin-3-gallate, Osteoporosis, Osteoclast, Proliferation, Estrogen receptor

Tropical Journal of Pharmaceutical Research is indexed by Science Citation Index (SciSearch), Scopus, International Pharmaceutical Abstract, Chemical Abstracts, Embase, Index Copernicus, EBSCO, African Index Medicus, JournalSeek, Journal Citation Reports/Science Edition, Directory of Open Access Journals (DOAJ), African Journal Online, Bioline International, Open-J-Gate and Pharmacy Abstracts

\section{INTRODUCTION}

Osteoporosis is a musculoskeletal disease characterized by low bone mineral density (BMD) and high risk of fragility fractures. Osteoporosis has drawn more and more attention from medical researchers because it is becoming an increasing risk for human health and quality of life [1]. Osteoporosis is caused by imbalance between bone formation and bone resorption, which relies on the interactions between osteoblasts and osteoclasts [2,3]. Osteoblasts, known as bone-forming cells, are the major osteoprogenitor cells, whose proliferation and differentiation will eventually result in the formation of the mineralized extracellular matrix [4].

To date, one effective solution to treat osteoporosis is targeted on osteoblasts by increasing the proliferation of the osteoblastic lineage and promoting the differentiation of osteoblasts, and eventually to induce new bone formation [5]. The functions of osteoblasts can be regulated by various local and hormonal factors such as Wnt glycoproteins. Canonical Wnt/betacatenin signaling pathway plays an important role in the maintenance of bone mass and bone 
formation [6]. Wnt ligands binding to the frizzled receptor will lead to accumulation and stabilization of beta-catenin in the cytoplasm [7]. Recent studies demonstrate that beta-catenin through Wnt signaling is essential in skeletal development through the regulation of osteoblastogenesis $[7,8]$.

Epigallocatechin-3-gallate (EGCG), a component of green tea, has been demonstrated to possess various biological activities, including anti-cancer, anti-inflammation, anti-bacteria and so on [9-11]. In the present study, we studied the effects of EGCG on bone metabolism regarding osteoblastic activity in MG-63 human osteoblastlike cells, and evaluated the possible underlying mechanisms.

\section{EXPERIMENTAL}

\section{Cell culture and cell viability assay}

Human osteoblast-like MG-63 cells were obtained from the Institute of Biochemistry and Cell Biology, the Chinese Academy of Science, Shanghai, China. The cells were cultured in Dulbecco's modified Eagle's medium (DMEM; Life Technologies, CA, USA), containing $10 \%$ fetal bovine serum (FBS; Life Technologies, CA, USA) and $1 \%$ penicillin and streptomycin (PS; Life Technologies, CA, USA) in a humidified incubator at $37{ }^{\circ} \mathrm{C}$ with $5 \% \mathrm{CO}_{2}$. Cell viability was determined by the 3-[4, 5-dimethylthiazol-2yl]-2, 5-diphenyltetrazolium bromide (MTT; Sigma, St. Louis, MO). MG-63 cells were plated in 96 -well plates $\left(5 \times 10^{3}\right.$ cells/well) and treated with various concentrations of EGCG $(7.5-30$ $\mu \mathrm{M})$ for three days. MTT solution at a concentration of $5 \mathrm{mg} / \mathrm{mL}$ was added into each well and incubated for another $2 \mathrm{~h}$. The optical density [12] at $540 \mathrm{~nm}$ was measured and expressed as the percentage of vehicle control.

\section{Alkaline phosphatase (ALP) activity assay}

ALP activity was determined using a commercial Alkaline Phosphatase Microwell Substrate System (Sigma, St. Louis, MO) following the manufacturer's instruction. After treatment with various concentrations of EGCG $(7.5-30 \mu \mathrm{M})$ for 4 days, the cell monolayer was gently rinsed twice with ice cold PBS and lysed with lysis buffer containing $0.1 \%$ Triton $X-100,50 \mathrm{mM}$ Tris$\mathrm{HCl}(\mathrm{pH} 7.2)$, and $2 \mathrm{mM} \mathrm{MgCl}$. The supernatant was collected after the lysate was centrifuged at $14,000 \mathrm{xg}$ for $10 \mathrm{~min}$ at $4{ }^{\circ} \mathrm{C}$. ALP activity in the clear supernatant was measured with ALP activity assay kit and the total protein concentration was determined with a BCAprotein assay kit.

\section{Matrix mineralization assay}

The degree of matrix mineralization of MG-63 cells was determined by Alizarin Red S staining method after EGCG treatment for 6 days [13]. Cells were washed twice with cold PBS and fixed with cold $70 \%$ ethanol $(\mathrm{v} / \mathrm{v})$ for $30 \mathrm{~min}$. Next, the cells were rinsed with distilled water and exposed to $40 \mathrm{mM}$ Alizarin Red S solution ( $\mathrm{pH} 4.2)$ for 10 min. After removing the unbonded stain by rinsing three times with distilled water, the amount of stain on the tested cells was extracted by shaking the cells with $10 \mathrm{mM}$ sodium phosphate containing $10 \%$ cetylpyridinium chloride (Sigma, USA) for $15 \mathrm{~min}$. The values were then determined at an optical density of 562 $\mathrm{nm}$. The data were expressed as percentage relative to the vehicle control group, after the relative matrix mineralization values were normalized by the relative cell viability.

\section{RNA extraction and quantitative real-time polymerase chain reaction (q-PCR)}

The expression of beta-catenin mRNA was evaluated by q-PCR. The total RNA was extracted with TRIzol® reagent (Life Technologies, NY, USA), according to the manufacturer's instructions. In the experiment, 1 $\mu \mathrm{g}$ RNA was used for the reverse transcription reaction using Oligo dT (18T) (Omega, NY, USA). Nucleotide sequences of primer for betacatenin were: forward, 5'-gccacaggattacaagaagc3'; reverse, 5'-ccaccagagtgaaaagaacg-3'.

In our experiment, PCR was carried out in duplicate with SYBR Green PCR Master Mix using a $7900 \mathrm{HT}$ qPCR system thermal cycler (Applied Biosystems, CA). Beta-actin mRNA was used as internal control for each sample. The $\mathrm{Ct}$ values for each sample were normalized to betaactin mRNA. Nucleotide sequences of primers for beta-actin were: forward, 5'-ttctacaatga gctgcgtgtg-3', reverse, 5'-ggggtgttgaaggtctcaaa3'. Results were shown for three independent experiments.

\section{Statistical analysis}

The data were shown as the mean \pm standard deviation from three independent tests. One-way analysis of variance (ANOVA) followed by Dunnett test was performed using Graph Pad Prism software version 5.0 for statistical analysis. In all experiments, $p<0.05$ was considered statistically significant. 


\section{RESULTS}

\section{Effects of EGCG on cell viability of MG-63 human osteoblast-like cells}

After treatment with various concentrations (7.5 $30 \mu \mathrm{M}$ ) of EGCG for 3 days, cell viability was determined by the MTT assay. The data showed that EGCG did not affect the cell viability of MG63 cells at the tested concentrations (Fig 1), indicating that EGCG was not cytotoxic to MG-63 human osteoblast-like cells.

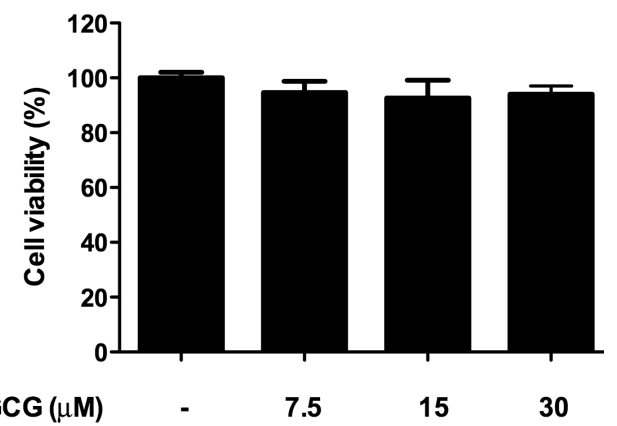

Fig 1: Effect of EGCG on cell viability of MG-63 human osteoblast-like cells. Values are expressed as mean \pm standard deviation $(\mathrm{n}=3) ; p>0.05$, compared with vehicle control

\section{Effects of EGCG on ALP activity of MG-63 human osteoblast-like cells}

In order to determine whether EGCG could increase osteoblastic cell differentiation, its effect on ALP activity as investigated. Our results showed that treatment of MG-63 cells with EGCG for 4 days dose-dependently stimulated ALP activity in the cells. ALP activity was remarkably increased by $37.1 \pm 10.6$ and $75.6 \pm$ $9.5 \%$ with EGCG treatment at 15 and $30 \mu \mathrm{M}$, respectively, when compared with the vehicle control group (Fig 2).

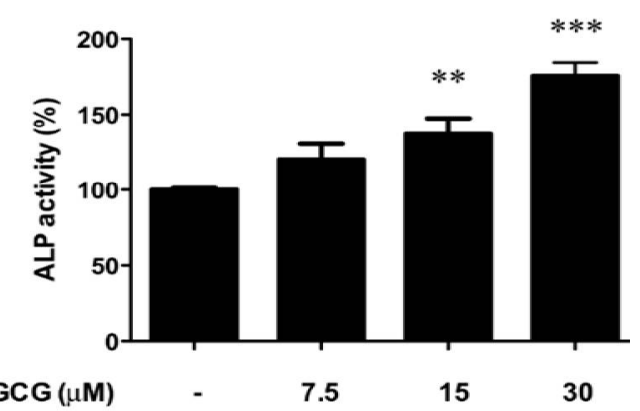

Fig 2: Effects of EGCG on ALP activity of MG-63 human osteoblast-like cells. Values are expressed as mean \pm standard deviation; ${ }^{* *} p<0.01,{ }^{* * *} p<0.001$ versus control group
Effect of EGCG on mineralization activity of MG-63 human osteoblast-like cells

The matrix mineralization assay was also evaluated for further studying the effects of EGCG on osteoblastic activity. The data demonstrated that EGCG treatment also significantly promoted the matrix mineralization at 15 and $30 \mu \mathrm{M}$, by $47.3 \pm 9.1$ and $82.7 \pm 15.2$ $\%$, respectively (Fig 3 ).

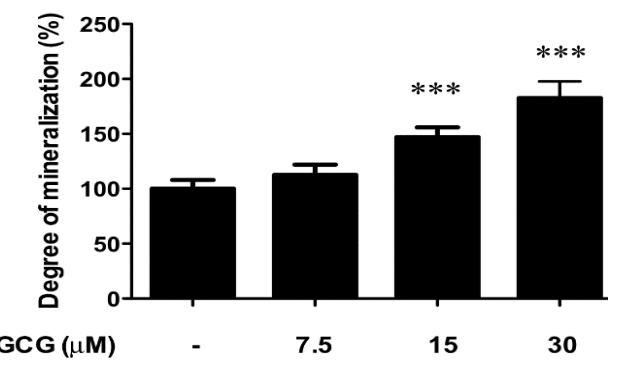

Fig 3: Effects of EGCG on mineralization activity of MG-63 human osteoblast-like cells. Values are expressed as mean \pm standard deviation; ${ }^{* * *} p<0.001$ versus control group

Effect of EGCG on beta-catenin mRNA expression in MG-63 human osteoblast-like cells

Beta-catenin is an important molecule for Wnt signaling pathway, which plays a crucial role in bone formation. Therefore, to determine whether Wnt signaling pathway was involved in the effects of EGCG on osteoblastic activity, betacatenin mRNA expression levels in MG-63 cells were evaluated after EGCG treatment. As shown in Fig 4, EGCG treatment significantly increased the beta-catenin mRNA expression. The betacatenin mRNA levels were increased by $70.7 \pm$ 11.0 and $126.7 \pm 35.1 \%$, respectively by EGCG treatment at 15 and $30 \mu \mathrm{M}$.

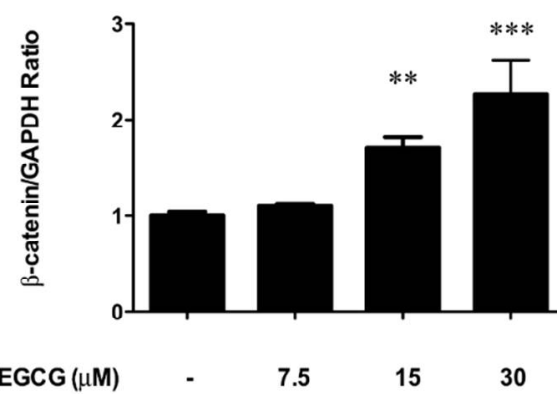

Fig 4: Effect of EGCG on beta-catenin mRNA expression in MG-63 human osteoblast-like cells. Values are expressed as mean \pm standard deviation; ${ }^{* *} p<0.01,{ }^{* \star *} p<0.001$ versus control group 
Effects of EGCG on osteoblastic activities in MG-63 human osteoblast-like cells after cotreatment with ICl182780

To determine whether estrogen receptor (ER) was involved in EGCG activated osteoblastic activities, ICl 182,780, an antagonist of ER was co-treated with EGCG on MG-63 cells. Our data showed that the stimulative effects of EGCG treatment on ALP activity were abolished by $\mathrm{ICl}$ $182,780(1 \mu \mathrm{g} / \mathrm{ml})$ co-treatment. In addition, the increasing mRNA level of beta-catenin by EGCG treatment was also inhibited by ICl 182,780 cotreatment (Fig 5).

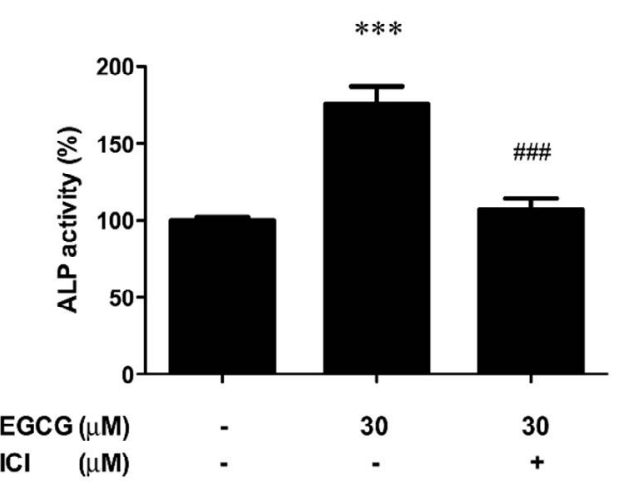

Fig 5: Effects of EGCG on osteoblastic activities of MG-63 human osteoblast-like cells after co-treatment with $\mathrm{ICl} 182780(1 \mu \mathrm{g} / \mathrm{ml})$. Values are expressed as mean \pm standard deviation; ${ }^{* *} p<0.01,{ }^{* * *} p<0.001$ versus control group

\section{DISCUSSION}

In the present study, EGCG was found to be capable of increasing ALP activity and mineralization activity, in a dose-dependent manner. Besides, EGCG treatment significantly increased after beta-catenin mRNA expression by $70.7 \pm 11.0$ and $126.7 \pm 35.1 \%$, respectively by EGCG treatment at 15 and $30 \mu \mathrm{M}$. Furthermore, the stimulating effects of EGCG treatment on ALP activity were abolished by cotreatment with $\mathrm{ICl} 182,780$, an antagonist of estrogen receptor (ER). In addition, the increasing mRNA level of beta-catenin by EGCG treatment was also inhibited by ICl 182,780 cotreatment.

Osteoblasts play an important role in the process of osteoporosis. Among various osteoblast differentiation markers, ALP is known as a representative marker for the early stage of differentiation, and is a critical indicator of the initiation of mineralization during bone formation [2]. In our results, EGCG could significantly increase ALP activity and also the mineralization activity, indicating that EGCG has great potential in promoting osteoblastic activities.

Wnt/beta-catenin pathway plays an essential role in bone mass accrual, regulation and maintenance [12]. Scientific evidence reveals that beta-catenin is an important mediator in the Wnt signaling pathway, which plays a crucial role in bone formation [14]. Researchers also find that deletion of the beta-catenin gene will inhibit the proliferation and differentiation of osteoblasts [15]. In the current study, EGCG significantly increased the beta-catenin mRNA in MG-63 cells, indicating that the Wnt/beta-catenin pathway is involved in the actions of EGCG in osteoblasts. ER also plays a significant role the probiferation and;:differentiation of osteoblasts, and subsequently bone remodeling and deyelopment of eleton [16].

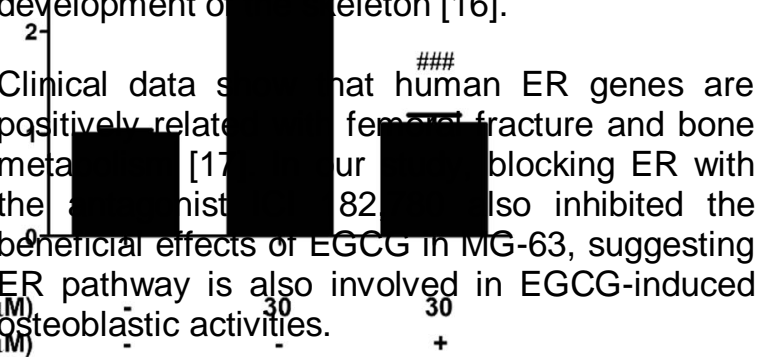

\section{CONCLUSION}

Taken together, the findings demonstrate that EGCG promotes osteoblastic activity in human osteoblast-like cells, which may involve Wnt signaling through ER pathway. All the findings strongly suggest that EGCG needs to be further studied with a view to developing an effective therapeutic agent for osteoporosis.

\section{REFERENCES}

1. Willson $T$, Nelson SD, Newbold J, Nelson RE, LaFleur J. The clinical epidemiology of male osteoporosis: $A$ review of the recent literature. Clin Epidemiol 2015; 7: 65-76.

2. Zhang C, Peng J, Wu S, Jin Y, Xia F, Wang C, Liu K, Sun $H$, Liu M. Dioscin promotes osteoblastic proliferation and differentiation via Irp5 and er pathway in mouse and human osteoblast-like cell lines. J Biomed Sci 2014; 21: 30-42.

3. Lee YS, Choi EM. Costunolide stimulates the function of osteoblastic mc3t3-e1 cells. Int Immunopharmacol 2011; 11: 712-718.

4. Ducy $P$, Schinke $T$, Karsenty $G$. The osteoblast: $A$ sophisticated fibroblast under central surveillance. Science 2000; 289: 1501-1504.

5. Lane NE, Kelman A. A review of anabolic therapies for osteoporosis. Arthritis Res Ther 2003; 5: 214-222. 
6. Zhou J, He H, Yang L, Chen S, Guo H, Xia L, Liu H, Qin $Y$, Liu C, Wei $X$, Zhou $Y$. Effects of pulsed electromagnetic fields on bone mass and wnt/betacatenin signaling pathway in ovariectomized rats. Arch Med Res 2012: 43: 274-282.

7. Wang $Y$, Li YP, Paulson $C$, Shao JZ, Zhang $X, W u M$, Chen W. Wnt and the wnt signaling pathway in bone development and disease. Front Biosci (Landmark Ed) 2014; 19: 379-407.

8. Hill TP, Spater D, Taketo MM, Birchmeier W, Hartmann C. Canonical wnt/beta-catenin signaling prevents osteoblasts from differentiating into chondrocytes. Dev Cell 2005; 8: 727-738.

9. Yang CS, Li G, Yang Z, Guan F, Chen A, Ju J. Cancer prevention by tocopherols and tea polyphenols. Cancer Lett 2013; 334: 79-85.

10. Singh R, Akhtar N, Haqqi TM. Green tea polyphenol epigallocatechin-3-gallate: Inflammation and arthritis. [corrected]. Life Sci 2010; 86: 907-918.

11. Steinmann J, Buer J, Pietschmann T, Steinmann E. Antiinfective properties of epigallocatechin-3-gallate (egcg), a component of green tea. Br J Pharmacol 2013; 168 : 1059-1073.

12. Robinson JA, Chatterjee-Kishore M, Yaworsky PJ, Cullen DM, Zhao W, Li C, Kharode Y, Sauter L, Babij P, Brown
$E L$, Hill AA. Wnt/beta-catenin signaling is a normal physiological response to mechanical loading in bone. $J$ Biol Chem 2006; 281: 31720-31728.

13. Ko CH, Lau KM, Choy WY, Leung PC. Effects of tea catechins, epigallocatechin, gallocatechin, and gallocatechin gallate, on bone metabolism. J Agric Food Chem 2009; 57: 7293-7297.

14. Kramer I, Halleux C, Keller H, Pegurri M, Gooi JH, Weber $P B$, Feng JQ, Bonewald LF, Kneissel M. Osteocyte wnt/beta-catenin signaling is required for normal bone homeostasis. Mol Cell Biol 2010; 30: 3071-3085.

15. Golovchenko S, Hattori T, Hartmann C, Gebhardt $M$, Gebhard S, Hess A, Pausch F, Schlund B, von der Mark $K$. Deletion of beta catenin in hypertrophic growth plate chondrocytes impairs trabecular bone formation. Bone 2013; 55: 102-112.

16. Borjesson AE, Lagerquist MK, Windahl SH, Ohlsson C. The role of estrogen receptor alpha in the regulation of bone and growth plate cartilage. Cell Mol Life Sci 2013; 70: 4023-4037.

17. Honma N, Mori S, Zhou H, Ikeda S, Mieno MN, Tanaka $N$, Takubo K, Arai T, Sawabe M, Muramatsu M, Ito $H$. Association between estrogen receptor-beta dinucleotide repeat polymorphism and incidence of femoral fracture. J Bone Miner Metab 2013; 31: 96-101. 